\title{
Recht vs. Technik: Zum Scheitern verurteilte Gesetzesinitiative zu § 362 StPO
}

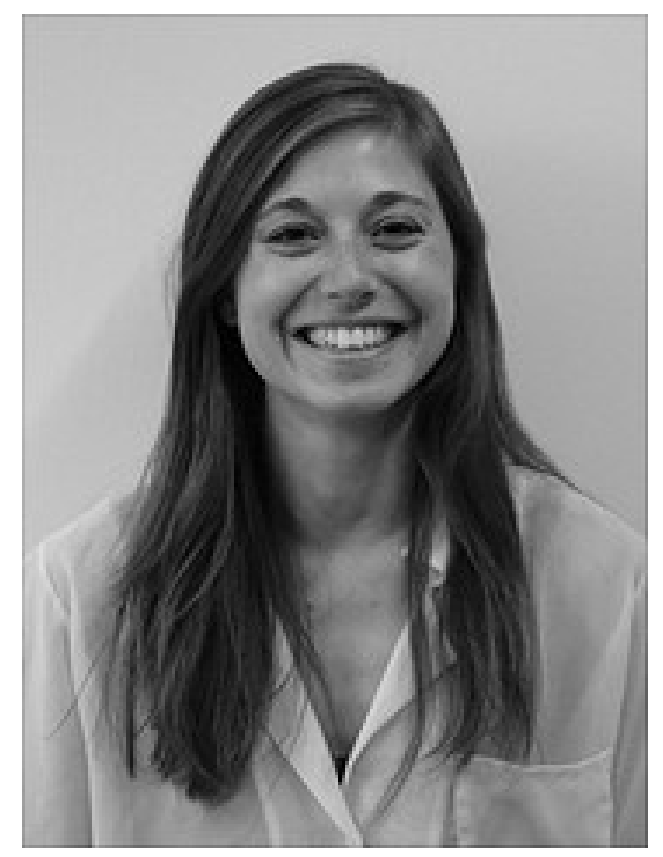

von DARIA BAYER

Mal wieder wird zur Zeit vom Bundesministerium für Justiz und Verbraucherschutz (BMJV) eine Gesetzesinitiative zur Erweiterung der Wiederaufnahmegründe zuungunsten der Angeklagten eines rechtskräftig abgeschlossenen Strafverfahrens nach $\$ 362$ StPO vorbereitet. Hiernach soll eine Wiederaufnahme eines rechtskräftig abgeschlossenen Verfahrens zu Lasten der Angeklagten bei Mord und den nach § 5 VStGB unverjährbaren Straftaten auch dann zulässig sein, wenn zum Zeitpunkt der Hauptverhandlung bereits vorliegende Beweisstücke durch neue kriminalistische Techniken wie etwa eine DNA-Analyse neu bewertet werden können. Also: Technische statt juristische Wahrheitsfindung?

\section{Wiederaufnahme zuungunsten der Angeklagten} verfassungsgemäß?

Aus verfassungsrechtlicher Sicht hat die Wiederaufnahme eines rechtskräftig abgeschlossenen Verfahrens mit dem aus dem Rechtsstaatsprinzip folgenden Prinzip der Rechtssicherheit zu kämpfen. Dieses gewinnt im Strafverfahren durch 
das in Art. 103 Abs. 3 GG niedergelegte „Verbot der Doppelbestrafung“ (ne bis in idem) eine besondere Bedeutung. Auch wenn Art. 103 Abs. 3 GG ausdrücklich nur besagt, dass „niemand wegen derselben Tat [...] mehrmals bestraft" werden darf, folgt hieraus im Wege eines sogenannten „Erst-recht-Schlusses“, dass auch niemand aufgrund derselben Tat mehrmals verfolgt werden darf: Wenn einer zu Recht Verurteilten schon nicht zugemutet werden kann, zweimal wegen derselben Tat verfolgt zu werden, so könne dies erst Recht nicht derjenigen zugemutet werden, die im ersten Verfahren freigesprochen und also - zumindest nach dem damaligen Erkenntnisstand - zu Unrecht verfolgt worden sei (Maunz/Dürig, GG-Kommentar, 92. EL August 2020, Art. 103 Abs. 3 Rn. 65). Aus dem „Doppelbestrafungsverbot“ des Art. 103 Abs. 3 GG folgt also auch ein „Mehrfachverfolgungsverbot“ bei rechtskräftigen Freisprüchen (explizit auch in Art. 4 Abs. 1 des 7. Zusatzprotokolls der EMRK zu finden).

Bereits die bloße Möglichkeit eines strafrechtlichen Prozesses kann große Auswirkungen auf das Leben der Betroffenen haben, die zu jedem Zeitpunkt mit der Möglichkeit der Strafverfolgung rechnen muss. § 362 StPO stößt deshalb schon in seiner jetzigen Fassung auf verfassungsrechtliche Bedenken. Nach der Rechtsprechung des Bundesverfassungsgerichts steht die Wiederaufnahme eines rechtskräftig abgeschlossenen strafrechtlichen Verfahrens „im Spannungsfeld zwischen den rechtsstaatlich verankerten Prinzipien der Rechtssicherheit [...] und der materialen Gerechtigkeit, die durch eine objektiv unrichtige Beurteilung einer Tat beeinträchtigt ist“" (Rn. 10). Grundsätzlich überwiege laut Bundesverfassungsgericht aber das Interesse an Rechtssicherheit und Rechtsfrieden die „Möglichkeit einer im Einzelfall vielleicht unrichtigen Entscheidung“ (Rn. 86).

362 StPO Nr. 1 bis Nr. 4 normieren in der aktuellen Fassung vier Gründe, aus denen ausnahmsweise die Rechtssicherheit zugunsten von materieller Gerechtigkeit durchbrochen werden darf - diese sind laut Bundesverfassungsgericht jedenfalls deshalb mit Art. 103 Abs. 3 GG vereinbar, weil dieser auf das zum Zeitpunkt des Inkrafttreten des Grundgesetzes „geltende Prozessrecht und seine Auslegung durch die herrschende Rechtsprechung“ (Rn. 12) Bezug nimmt. § 362 StPO wird dogmatisch teilweise als eine „verfassungsimmanente Schranke“ von Art. 103 Abs. $3 \mathrm{GG}$ ausgelegt. Das Vertrauen der Freigesprochenen auf den Freispruch ist nach § 362 StPO ausnahmsweise dann nicht schutzwürdig, wenn manipulativ auf das Urteil eingewirkt wurde ( $\$ 362 \mathrm{Nr}$. 1 bis 3 StPO) oder die Angeklagte sich nach dem Freispruch öffentlich mit der Tat rühmt ( $\$ 362$ Nr. 4 StPO). Dann nämlich wird das kollektive Vertrauen in die Rechtsordnung durch das fehlerhafte Urteil derart erschüttert, dass eine Wiederaufnahme zur Herstellung materialer Gerechtigkeit geboten erscheint.

Anders als $\S 359$ StPO Nr. 5 (Wiederaufnahme zugunsten der Angeklagten) kennt $\S 362$ StPO den Wiederaufnahmegrund der "neuen Tatsachen" (propter nova) gerade nicht. Im Entwurf zur aktuellen Gesetzesinitiative soll § 362 StPO nun um eine Nr. 5 erweitert werden und eine Wiederaufnahme zulasten der Angeklagten bei $\S 211$ StGB und den nach $\S 5$ VStGB nicht verjährbaren Verbrechen auch möglich werden, wenn aufgrund von neuen kriminalistischen Techniken bereits bekannte Beweismittel neu bewertet werden könnten. Also: Big data for big crimes? 
Das klingt zunächst durchaus einleuchtend, stößt aber aus zwei Gründen auf verfassungsrechtliche Bedenken: Der Stand der Technik ändert sich ständig und, noch viel wichtiger: Daten können Lügen.

\section{Recht, Technik, Wahrheit}

Interessant wird damit die Frage, welche Rolle dem Fortschritt der Technik generell im juristischen (Straf-)Verfahren zukommen soll. Der Gedanke, dass wir durch immer neuen kriminalistischen Technikfortschritt „mehr" Wahrheit im Strafprozess erlangen können, ist verlockend. Nichtsdestotrotz bleibt dieser Glaube an eine absolute prozessuale Wahrheit eine reine Illusion. Wir müssen nicht erst zu dystopischen Romanen wie Corpus Delicti von Juli Zeh greifen, um zu erkennen, dass das Erheben und Zuordnen von Daten, egal wie weit fortgeschritten die kriminalistische Technik zu einem gewissen Zeitpunkt $x$ ist, keine absolute, für alle Zeiten objektiv richtige Erkenntnis bringen kann. Dies verdeutlicht gerade bei der Auswertung von DNA etwa der berühmte Fall des Phantoms von Heilbronn. Und zwar deshalb, weil sie - wie alle Technik - von Menschen gemacht und von Menschen zu einem bestimmten Zweck eingesetzt werden. Wie schon Herbert Marcuse feststellte: Technik ist nicht neutral, sie ist zugleich Fluch und Segen. Sie kann sowohl der Befreiung des Menschen als auch zu dessen Unterdrückung dienten. Es kommt immer darauf an, zu welchem Zweck sie eingesetzt wird. Wer also definiert den Zweck der Technik? Die Politik, das Recht - oder die Technik selbst?

Es geht hier also nicht nur um das Spannungsverhältnis zwischen Gerechtigkeit und Rechtssicherheit, sondern auch um die grundlegende Frage, wer die letztendliche Macht über die rechtliche Wahrheitsfindung hat. Diese Autorität sollte das Recht in einer freiheitlich verfassten Gesellschaft zumindest in den Bereichen nicht leichtfertig zugunsten der Technik aufgeben, in denen es um den Kern des subjektiven Rechts geht: die Möglichkeit, ein freies, selbstbestimmtes Leben ohne Angst vor staatlicher Verfolgung zu führen. Der Stand der Technik kann sich immer wieder erneuern, aber die Aufgabe des Rechts ist es, zu einem gewissen Zeitpunkt eine verbindliche Entscheidung zu treffen und so Vertrauen in seine eigene Autorität zu schaffen. Gerade das garantiert Art. 103 Abs. 3 GG.

\section{Sisyphos lässt grüßen}

In der Vergangenheit sind bereits einige Erweiterungsinitiativen zu § 362 StPO gescheitert. Es ist in Zeiten von Verschwörungsnarrativen und Fake News verständlich, dass der Wunsch nach objektiver Wahrheit und rächender Gerechtigkeit wächst, die mit starker Hand die auseinanderdriftenden Grundfesten der demokratischen Grundordnung wieder zusammendrücken. Es ist also zu erwarten, dass dies nicht die letzte zum Scheitern verurteilte Gesetzesinitiative zu § 362 StPO bleiben wird. Das konstante Abwehren dieser Vorstöße ist die Sisyphosarbeit des Mehrfachverfolgungsverbots. 
Zitiervorschlag: Daria Bayer, Recht vs. Technik: Zum Scheitern verurteilte Gesetzesinitiative zu § 362 StPO, JuWissBlog Nr. 14/2021 v. 09.02.2021, https:// www.juwiss.de/14-2021/.

\section{(9) $(1) \Theta \Theta$}

Dieses Werk ist lizenziert unter einer Creative Commons Namensnennung - Nicht kommerziell - Keine Bearbeitungen 4.0 International Lizenz. 